\title{
Simulation Model of Single-Phase Simplified Eleven-Level Inverter
}

\author{
I. William Christopher \\ Senior Assistant Professor/Dept.of EEE \\ Tagore Engineering College \\ Chennai-600127, India
}

\author{
R. Ramesh, Ph.D \\ Associate Professor/Dept.of EEE \\ CEG, Anna University \\ Chennai-600127, India
}

\begin{abstract}
This paper presents simulation model of a single phase simplified eleven-level inverter (SELI). Multilevel inverter offers high power capability. Its performance is highly superior to that of conventional two-level inverter due to reduced harmonic distortion, lower electromagnetic interference and higher dc link voltage. The inverter is capable of producing eleven levels of output voltages ( $\mathrm{Vdc}$, $4 \mathrm{Vdc} / 5,3 \mathrm{vdc} / 5,2 \mathrm{Vdc} / 5, \mathrm{Vdc} / 5,0,-\mathrm{Vdc} / 5,-2 \mathrm{Vdc} / 5,-3 \mathrm{Vdc} / 5$, $-4 \mathrm{Vdc} / 5,-\mathrm{Vdc}$ ) from the DC supply voltage. Theoretical predictions are validated using MATLAB Simulink tool box.
\end{abstract}

\section{Keywords}

Capacitor clamped, diode clamped, multilevel inverter, $\mathrm{H}$ bridge, Simplified Eleven-level Inverter (SELI).

\section{INTRODUCTION}

In the area of power electronics, multilevel power converters are growing rapidly. The output voltage of multilevel inverters is synthesized from many discrete smaller voltage levels. It can also be viewed as voltage synthesizers. The different multilevel inverter topologies [1] are discussed. It has many advantages over two-level inverters, such as:

\section{Stepped waveform with less distortion;}

2.Lower switching frequency;

3.Higher efficiency;

4. Lower voltage power devices.

Though it has many advantages, there are some disadvantages too that are associated with the multilevel configurations. Like their circuit complexity which requires a large number of power switches that must be commutated in a accurately determined sequence by a dedicated control circuit; it also require a great number of auxiliary dc levels which are provided either by independent supplies or, more commonly, by a cumbersome array of capacitive voltage dividers. The complexity of the control circuit also increases due to the fact that the dc voltages have to be kept in equilibrium.

These disadvantages were huge due to the cost differences produced between multilevel and standard configurations. Multilevel converters were used only in some high power applications which include high power motor drivers, Power distribution and power conditioning. [2]-[7]. The work reports a generalized, simplified multilevel configuration as shown in Fig. 1. The topology includes an H-bridge which consists of four main switches with an auxiliary bidirectional switch [8][11]. This configuration significantly reduces the complexity of power circuit.
These two concepts are used in the development of the eleven-level bridge converter presented below. The lower component count and the reduced layout complexity have been achieved in the proposed configuration when compared with the other multilevel inverters presented in the literature [12], [13]. Almost a $40 \%$ of main power switches are reduced in the new configuration with no more diodes and capacitors when compared with asymmetric cascade configuration [1].

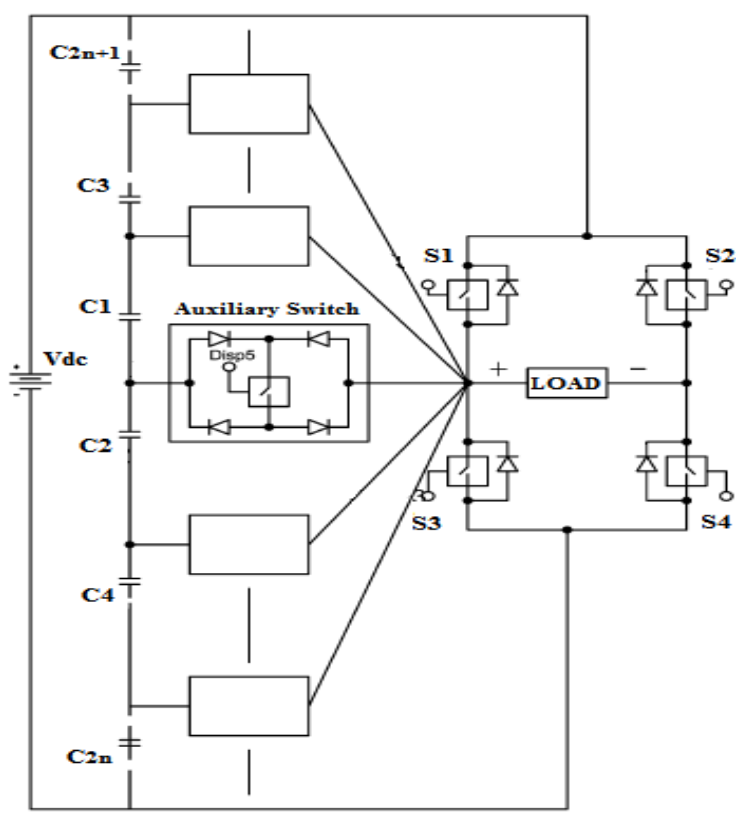

Fig 1: Generalized simplified multilevel configuration

This paper is organized as follows. First, the power circuit configuration and its advantages presented in section 2 . Then, the power circuit operation includes the modes of operation is discussed in section 3. Section 4 describes the simulation results and functionality verification of the eleven-level inverter circuit. Last section concludes and the scope for further work is presented.

\section{POWER CIRCUIT}

\subsection{Power Circuit Advantages}

A single phase simplified multilevel inverter has the following merits over other existing multilevel inverter topologies.

1.Improved output waveforms.

2. Reduced number of switches employed.

3.Less complexity of the circuit as the levels increase. 


\section{Smaller filter size.}

5.Lower electromagnetic interference and total harmonic distortion.

In addition to this, the capacitors are connected in parallel with the main DC power supply, no significant capacitor voltage swing is produced during normal operation, avoiding a problem that can limit operating range in some other multilevel configurations.

\subsection{Power Circuit Description}

The proposed single phase simplified eleven-level inverter was developed from the five-level inverter.

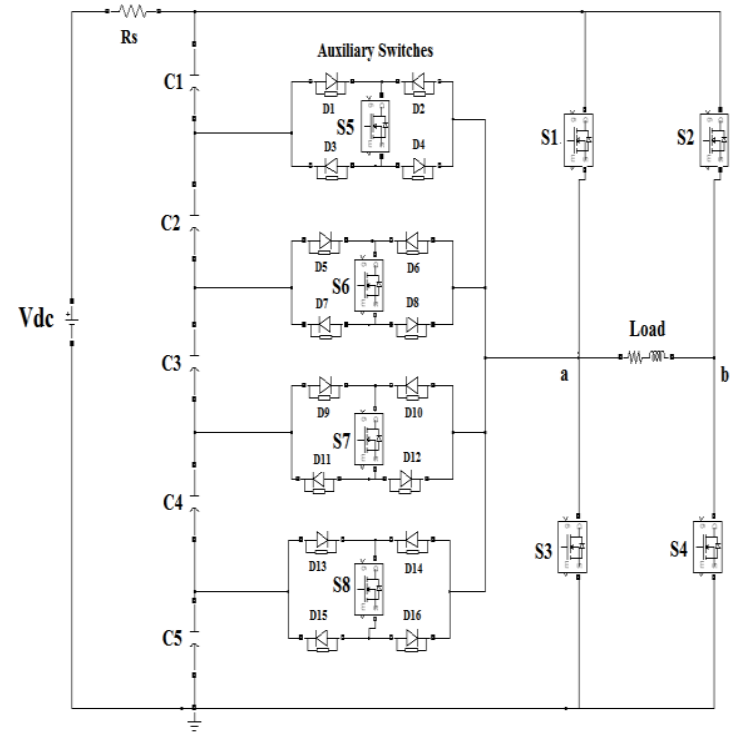

Fig 2: Simplified Eleven-level inverter circuit

It consists of a single phase conventional H-bridge inverter, four bidirectional switches and a capacitor voltage divider formed by $\mathrm{C}_{1}, \mathrm{C}_{2}, \mathrm{C}_{3}, \mathrm{C}_{4}, \mathrm{C}_{5}$ as shown in Fig.2. The auxiliary switches formed by the controlled switch $\mathrm{S}_{5}, \mathrm{~S}_{6}, \mathrm{~S}_{7}, \mathrm{~S}_{8}$ and with sixteen diodes $\mathrm{D}_{1}$ to $\mathrm{D}_{16}$.

\section{POWER CIRCUIT}

The inverter is capable of producing eleven levels of output voltages $(\mathrm{Vdc}, 4 \mathrm{Vdc} / 5,3 \mathrm{Vdc} / 5,2 \mathrm{Vdc} / 5, \mathrm{Vdc} / 5,0,-\mathrm{Vdc} / 5$, $-2 \mathrm{Vdc} / 5,-3 \mathrm{Vdc} / 5,-4 \mathrm{Vdc} / 5$ and $-\mathrm{Vdc})$ from the DC supply voltage $\mathrm{Vdc}$ shown in fig.3.

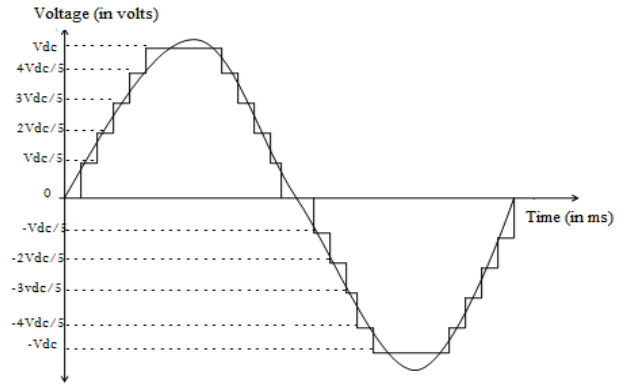

Fig 3: Eleven-level inverter output wave form.

There are eleven modes of operation in which two switches conduct for every modes of operation, while other switches remains in OFF position The different voltage levels of the inverter can be synthesized from the following modes of operation and can be understood using table. I.

\subsection{Mode I Operation}

During mode I operation switches S1 and S4 are turned ON providing an output voltage level of Vdc volts.

\subsection{Mode I Operation}

During mode II operation switches S4 and S5 are turned ON providing an output voltage level of $4 \mathrm{Vdc} / 5$ volts.

Table 1. Switching combinations required to generate the eleven-level output

\begin{tabular}{|c|c|c|c|c|c|c|c|c|}
\hline \multirow{2}{*}{$\begin{array}{c}\text { Voltage } \\
\text { Level }\end{array}$} & \multicolumn{7}{|c|}{ Switches } \\
\cline { 2 - 9 } & S1 & S2 & S3 & S4 & S5 & S6 & S7 & S8 \\
\hline Vdc & 1 & 0 & 0 & 1 & 0 & 0 & 0 & 0 \\
\hline 4Vdc/5 & 0 & 0 & 0 & 1 & 1 & 0 & 0 & 0 \\
\hline 3Vdc/5 & 0 & 0 & 0 & 1 & 0 & 1 & 0 & 0 \\
\hline 2Vdc/5 & 0 & 0 & 0 & 1 & 0 & 0 & 1 & 0 \\
\hline Vdc/5 & 0 & 0 & 0 & 1 & 0 & 0 & 0 & 1 \\
\hline $\mathbf{0}$ & 1 & 1 & 0 & 0 & 0 & 0 & 0 & 0 \\
\hline $\mathbf{0} *$ & 0 & 0 & 1 & 1 & 0 & 0 & 0 & 0 \\
\hline -Vdc/5 & 0 & 1 & 0 & 0 & 1 & 0 & 0 & 0 \\
\hline $\mathbf{- 2 V d c / 5}$ & 0 & 1 & 0 & 0 & 0 & 1 & 0 & 0 \\
\hline $\mathbf{- 3 V d c / 5}$ & 0 & 1 & 0 & 0 & 0 & 0 & 1 & 0 \\
\hline $\mathbf{- 4 V d c / 5}$ & 0 & 1 & 0 & 0 & 0 & 0 & 0 & 1 \\
\hline
\end{tabular}

\subsection{Mode I Operation}

During mode III operation switches S4 and S6 are turned ON providing an output voltage level of $3 \mathrm{Vdc} / 5$ volts.

\subsection{Mode I Operation}

During mode IV operation switches S4 and S7 are turned ON providing an output voltage level of $2 \mathrm{Vdc} / 5$ volts.

\subsection{Mode I Operation}

During mode V operation switches S4 and S8 are turned ON providing an output voltage level of $\mathrm{Vdc} / 5$ volts.

\subsection{Mode I Operation}

This mode of operation has two possible switching combinations. Either switches S3 and S4 are ON or S1 and S2 are ON providing an output voltage level of 0 volts.

\subsection{Mode I Operation}

During mode VII operation switches S2 and S5 are turned ON providing an output voltage level of $-\mathrm{Vdc} / 5$ volts.

\subsection{Mode I Operation}

During mode VIII operation switches S2 and S6 are turned $\mathrm{ON}$ providing an output voltage level of $-2 \mathrm{Vdc} / 5$ volts.

\subsection{Mode I Operation}

During mode IX operation switches S2 and S7 are turned ON providing an output voltage level of $-3 \mathrm{Vdc} / 5$ volts.

\subsection{Mode I Operation}

During mode X operation switches S2 and S8 are turned ON providing an output voltage level of $-4 \mathrm{Vdc} / 5$ volts. 


\subsection{Mode I Operation}

During mode XI operation switches S2 and S3 are turned ON providing an output voltage level of $-\mathrm{Vdc}$ volts.

In the eleven-level inverter circuit five capacitors in the capacitive voltage divider are connected directly across the dc supply voltage $\mathrm{Vdc}$, and since all switching combinations are activated in an output cycle, the dynamic voltage balance between the five capacitors is automatically restored.

\section{SIMULATION RESULTS}

The simulation model of the single-phase simplified elevenlevel inverter (SELI) using MATLAB Simulink tool box is shown in Fig.4.This model, developed using the Simulink power system block set, comprises of components such as power electronic devices (MOSFETs) and elements such as capacitors and resistors.

The PWM signals for each of the switching devices in the power circuit come from the PWM block. This block includes all the PWM signals required for switches are multiplexed on a single bus to the eleven -level inverter power circuit. The switching sequence required to generate eleven levels of output voltage for the simplified eleven-level inverter (SELI) circuit is shown in Fig. 5.

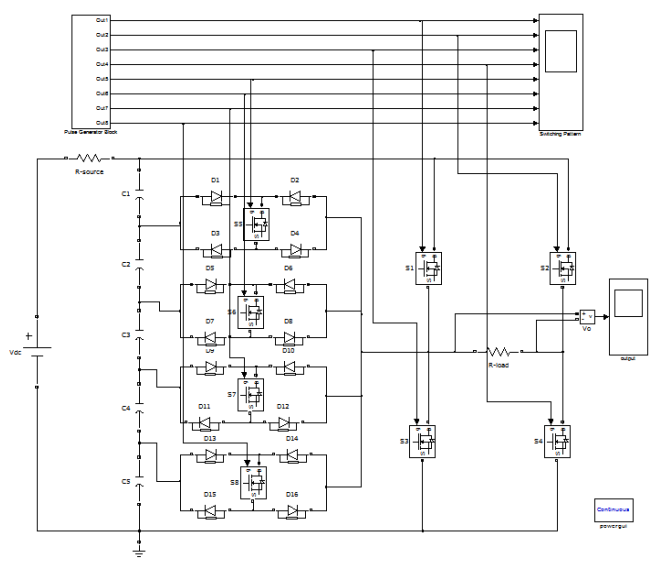

Fig 4: Single-phase SELI Simulation circuit.

Switching Sequence for Switches: S1-S8

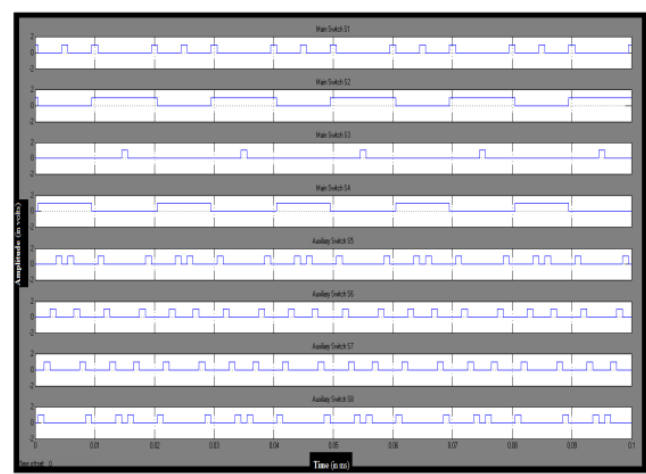

Fig 5: Switching sequence required for SELI circuit.

Fig. 6 shows the simulated eleven-level output voltage waveform of the SELI circuit.
Eleven-Level Output Voltage

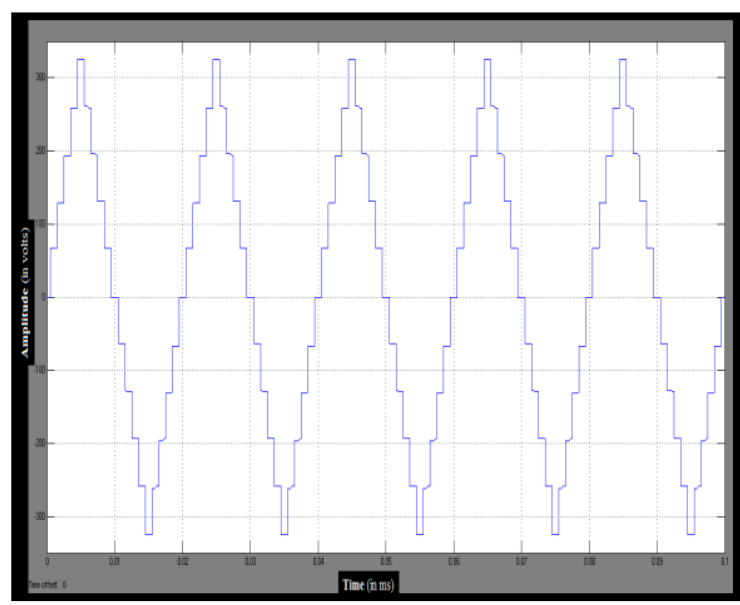

Fig 6: Simulated output voltage waveform of the simplified eleven-level inverter (SELI) circuit ( $\mathrm{V}_{\mathrm{dc}}$ bus $=325 \mathrm{~V}$; Load: $\mathrm{R}=20 \mathrm{~K} \Omega$,

Vertical: 100V/d. Horizontal: 10ms/div)

It is clearly visible that the simulated output waveform is very close to the ideal output defined for a simplified eleven-level inverter (SELI) circuit. The eleven-levels of voltages are $\mathrm{V}_{\mathrm{dc}}=$ $325 \mathrm{~V}, 4 \mathrm{~V}_{\mathrm{dc}} / 5=260 \mathrm{~V}, 3 \mathrm{~V}_{\mathrm{dc}} / 5=195 \mathrm{~V}, 2 \mathrm{~V}_{\mathrm{dc}} / 5=130 \mathrm{~V}, \mathrm{~V}_{\mathrm{dc}}$ $15=65 \mathrm{~V}, 0 \mathrm{~V},-\mathrm{V}_{\mathrm{dc}} / 5=-65 \mathrm{~V},-2 \mathrm{~V}_{\mathrm{dc}} / 5=-130 \mathrm{~V},-3 \mathrm{~V}_{\mathrm{dc}} / 5=$ $195 \mathrm{~V},-4 \mathrm{~V}_{\mathrm{dc}} / 5=-260 \mathrm{~V},-\mathrm{V}_{\mathrm{dc}}=-325 \mathrm{~V}$

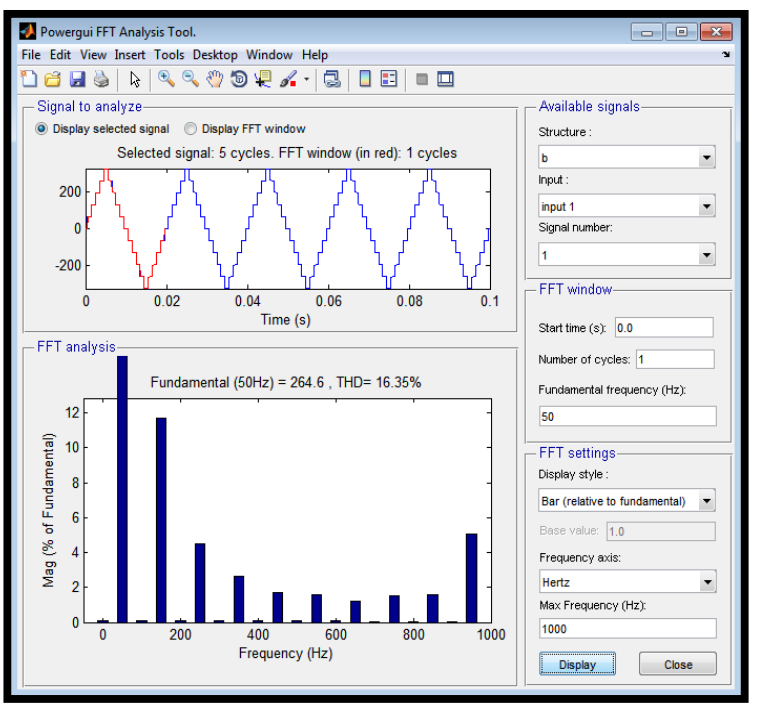

Fig 7: Total Harmonic Distortion for SELI

The Total Harmonic Distortion (THD) of the eleven- level inverter is observed that $16.35 \%$ and fundamental voltage is 264.6V $(50 \mathrm{~Hz})$ that has been illustrated in Fig. 7

\section{CONCLUSION}

This paper presented a simulation model of a single-phase simplified eleven-level inverter with resistive load using MATLAB Simulink tool box. The inverter model developed was shown to provide accurate results and provided valuable insight into eleven-level inverter performances.

A further development of the eleven- level inverter, able to be applied to any number of voltage levels within the power switches maximum voltage, is now under consideration. 


\section{ACKNOWLEDGMENTS}

The authors wish to thank the Management, Principal and the Department of Electrical and Electronics Engineering of Tagore Engineering College, Chennai for their whole hearted support and providing the laboratory facilities to carry out this work.

\section{REFERENCES}

[1] J. Rodriguez, J.-S. Lai, and F. Z. Peng, "Multi-level inverter: a survey of topologies, controls, and applications," IEEE Trans. Ind. Electron.,vol. 49, no. 4, pp. 724-738, Aug. 2002.

[2] M. Marchesoni and P. Tensa, "Diode-clamped multilevel converters: a practicable way to balance DC-link voltages," IEEE Trans. Ind. Electron., vol. 49, no. 4, pp. 752-765, Aug. 2002.

[3] L. M. Tolbert and T. G. Habertler, "Novel multilevel inverter carrier-based PWM method," IEEE Trans. Ind. Appl., vol. 35, no. 5, pp.1098-1107, Sep./Oct. 1999.

[4] X. Yuan and I. Barbi, "A New Diode Clamping Multilevel Inverter," IEEE Trans. Power Electron. vol. 15, no. 4, pp. 711-718, Jul. 2000.

[5] M. D. Majrekar, P. K. Steimer, and T. A. Lipo, "Hybrid multilevel power conversion system: a competitive solution for high-power applications," IEEE Trans. Ind. Appl.., vol. 36, no. 3, pp. 834-841, May/Jun.2000.

[6] L. M. Tobert, F. Z. Peng, T. Cunnyngham, and J. N. Chiasson, "Charge balance control schemes for cascade multi-level converter in hybrid electric vehicles," IEEE Trans. Ind. Electron., vol. 49, no. 5, pp.1058-1064, Oct. 2002.
[7] F. Z. Peng, J. W. McKeever, and D. J. Adams, "A power line conditioner using cascade multi-level inverters for distribution systems," IEEE Trans. Ind. Appl., vol. 34, no. 6, pp. 1293-1298, Nov./Dec. 1998.

[8] Geardo Ceglia, Victor Guzman, Carlos Sanchez, Fernando Ibanez, Julio Walter and Maria I. Gimenez, "A New Simplified Multilevel Inverter Topology for DCAC Conversion," IEEE Transactions on Power Electronics, vol.21,no.5,pp.1311-1319,September 2006.

[9] I.William Christopher, R.Ramesh, "Implementation of PIC16F877A Controlled Low Cost Single-Phase Five level Inverter with Fewer Switches," International Review on Modelling and Simulations (IREMOS), Part A,vol.5,no.1,pp.114-120,February 2012.

[10] I.William Christopher, R.Ramesh, et.al, "Microcontroller Based Single-Phase Simplified Seven-Level Inverter for PV System," in Proc. IEEE 5th India International Conference on Power Electronics IICPE 2012, December 2012.

[11] I.William Christopher, R.Ramesh, et.al, "Microcontroller Based Single-Phase Simplified Nine-Level Inverter fed Induction Motor," in Proc. IEEE 5th India International Conference on Power Electronics IICPE 2012, December 2012.

[12] F. Tourkhani, P. Viarouge, and T. A. Meynard, "A simulation-optimization system for the optical design of a multilevel inverter," IEEE Trans.Power Electronics., vol.14, no.6, pp.1037-1045, Nov. 1999.

[13] K. A. Corzine and X. Kou, "Capacitor voltage balancing in full binary combination schema flying capacitor multilevel inverters," IEEE Power Electron. Lett., vol. 1, no. 1, pp. 2-5, Mar. 2003. 